\section{ERCP cannulation of a hidden papilla within a duodenal diverticulum}

In expert hands, bile duct access using endoscopic retrograde cholangiopancreatography (ERCP) is almost always successful [1]. Nevertheless, to achieve deep common bile duct (CBD) cannulation, a great variety of techniques and devices must sometimes be employed by the biliary endoscopist [2]. A hidden papilla within a duodenal diverticulum is sometimes challenging. A case is presented here in which two special techniques of bile duct cannulation were used ( $\bullet$ Video 1 ).

An 83-year-old woman was admitted because of jaundice. Magnetic resonance cholangiography showed dilation of the CBD duct secondary to a possible stricture in the distal CBD. An ERCP was carried out with a therapeutic duodenoscope. The usual papillary location in the second duodenal portion was occupied by a diverticulum. In its left edge (in the endoscopic view), the papillary frenulum could be identified, although the papilla itself was completely hidden within the diverticulum. To evert the papillary orifice, two devices were employed simultaneously through the working channel [3]. A cannula (Glotip, Cook Medical, Winston-Salem, North Carolina, USA) served to maintain the papillary orifice out of the diverticulum, and a sphincterotome loaded with a 0.025 inch hydrophilic guide wire (Tapertome, Boston Scientific, Natick, Massachusetts, USA) was used to cannulate ( $\bullet$ Fig. 1). Initially, the guide wire entered the pancreatic duct. The guide wire was left in place there while the sphincterotome was withdrawn. A new attempt to cannulate above the previously placed pancreatic guide wire suc-

\section{Video 1}

Papilla located in the left edge of a duodenal diverticulum but completely hidden. Two devices were employed. A cannula served to evert the papillary orifice and a sphincterotome with a guide wire was used to cannulate. Initially, the guide wire entered the pancreatic duct and was left there. Cannulation above it succeeded in gaining access to the bile duct.

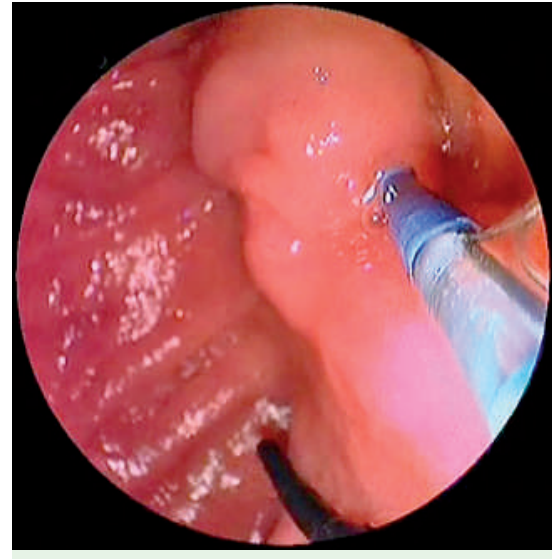

Fig. 1 To evert the papillary orifice outside the diverticulum, two devices were employed simultaneously through the working channel. The black tip of a cannula, which served to maintain the papillary orifice everted, is seen at the bottom of the image. A sphincterotome loaded with a 0.025 inch hydrophilic guide wire was used to cannulate the papilla.

ceeded in gaining access to the bile duct $[4,5]$.

The CBD dilation was probably secondary to papillitis or to impaired bile duct flow, due to the distorted position of the distal CBD in the diverticulum. A biliary sphincterotomy was performed. There were no complications.

This case can illustrate that, apart from a long learning curve [6], ERCP endoscopists have to perform the procedure frequently in order to be able to respond quickly enough to the multiple challenges that every single ERCP can present.

Endoscopy_UCTN_Code_TTT_1AR_2AB

\section{J. García-Cano}

Section of Digestive Diseases, Hospital

Virgen de la Luz, Cuenca, Spain

\section{References}

1 Guda NM, Freeman ML. 30 years of ERCP and still the same problems? Endoscopy 2007; 39: $833-835$

2 García-Cano J, González-Martín JA. Bile duct cannulation: success rates for various ERCP techniques and devices at a single institution. Acta Gastroenterol Belg 2006; 69: 261-267

3 Fujita N, Noda Y, Kobayashi G et al. ERCP for intradiverticular papilla: two-devices-inone-channel method. Gastrointest Endosc 1998; 48: $517-520$

4 Maeda S, Hayashi H, Hosokava O et al. Prospective randomized pilot trial of selective biliary cannulation using pancreatic guidewire placement. Endoscopy 2003; 35: $721-724$

5 Gyökres T, Duhl J, Varsányi M et al. Double guide wire placement for endoscopic pancreatobiliary procedures. Endoscopy 2003; 35: $95-96$

6 García-Cano J. 200 supervised procedures: the minimum threshold number for competency in performing endoscopic retrograde cholangiopancreatography. Surg Endosc 2007; 21: $1254-1255$

Bibliography

DOI 10.1055/s-2007-967055

Endoscopy 2008; 40: E53

(c) Georg Thieme Verlag KG Stuttgart · New York . ISSN 0013-726X

Corresponding author

J. García-Cano, MD

Section of Digestive Diseases

Hospital Virgen de la Luz

16002 Cuenca

Spain

Fax: +34-969-230407

j.garcia-cano@terra.es 